\title{
Biologic therapy for autoimmune diseases: an update
}

\author{
Ziv Rosman ${ }^{1}$, Yehuda Shoenfeld ${ }^{2,3}$ and Gisele Zandman-Goddard ${ }^{1,3^{*}}$
}

\begin{abstract}
Biologic therapies for rheumatologic diseases, which are targeted at molecules involved in the mechanisms of the immune system, provide an alternative to the existing treatment methods of disease-modifying anti-rheumatic drugs and other immunosuppressive medications. However, the current drawbacks of biologic therapies, including the inconvenience of intravenous administration, the high costs of these drugs, and the adverse events associated with them, prevent their wide use as first-line medications. This review provides an update of the recent literature on the new biologic therapies available. The review concentrates on nine drugs: tocilizumab, rituximab, ofatumumab, belimumab, epratuzumab, abatacept, golimumab, certolizumab, and sifalimumab, which are used as therapies for rheumatoid arthritis, spondyloarthritis, systemic lupus erythematosus, systemic sclerosis, or vasculitis.
\end{abstract}

Keywords: Biologics, Anti-TNF, B cell depletion, Autoimmune diseases, Rheumatoid arthritis, Spondyloarthritis, Systemic lupus erythematosus, Systemic sclerosis, Vasculitis

\section{Introduction}

The use of biologic therapies as an adjunct to diseasemodifying anti-rheumatic drugs (DMARDs) for the treatment of autoimmune and rheumatologic diseases is rapidly expanding, owing to the good efficacy and safety profiles of these drugs, and the better understanding of the initial targets of altered immune regulation and activity in various diseases. Targeted therapies such as these are often well tolerated by patients. However, the inconvenience of intravenous (IV) administration, as well as the high costs and adverse events (AEs) associated with these drugs prevent their wide use as first-line medications. The major targets of most biologic therapies are cytokines, B cells, and co-stimulation molecules. Anticytokines include anti-tumor necrosis factor (TNF)- $\alpha$, anti-interleukin (IL)-1, and anti-IL-6 molecules. B-cell depletion includes use of anti-CD20 antibodies and B cell receptor (BCR) modulation by the B-lymphocyte stimulator (BLyS). Although some of the biologic therapies have been found to be useful in more than one disease, others are specific for a single disease. Research is ongoing to identify other molecular targets.

\footnotetext{
* Correspondence: goddard@wolfson.health.gov.il

'Department of Medicine C, Wolfson Medical Center, 61 Halochamim Street, POB 63, Holon, 58100 Israel

${ }^{3}$ Sackler Faculty of Medicine, Tel-Aviv University, Tel-Aviv, Israel

Full list of author information is available at the end of the article
}

In this review, we provide an update on some of the new agents that have become available in the past 5 years for clinical treatment of rheumatoid arthritis (RA), spondyloarthropathy, systemic sclerosis (SyS), systemic lupus erythematosus (SLE), and vasculitis.

\section{Methods}

We performed a thorough literature review of all papers in English published in PubMed during the period 1 January 2007 to 30 April 2012. We matched the terms: 'rheumatoid arthritis', 'spondyloarthropathy', 'systemic sclerosis,' 'systemic lupus erythematosus', and 'vasculitis' with the terms 'biologics,' 'tocilizumab, 'rituximab,' 'ofatumumab, 'belimumab', 'epratuzumab', 'abatacept,' 'golimumab', 'certolizumab', and 'sifalimumab'. Reports of randomized controlled trials (RCTs) and case series were included. Case reports and any reports of biologic therapies that are not yet available for clinical use were excluded. We excluded articles that were in a language other than English.

\section{Screening for biologic treatment}

Over a decade has passed since the introduction of biologic therapies for autoimmune diseases. Currently, screening is routine practice prior to administration of these drugs, and is often performed during the initial visits to the outpatient clinic to prevent unnecessary waits for the

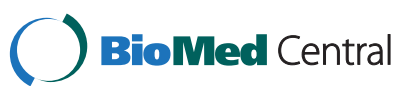


patient when a biologic is indicated. Screening consists of evaluation for previous or current tuberculosis (TB) infection (based on history, purified protein derivative (PPD) test, chest radiography), serological evidence of hepatitis B and C, history of malignancies or neurological disease. Based on the screening results, the physician will assess which biologic treatment is recommended or if prior treatment is warranted before the initiation of the biologic therapy. The choice of biologic agent for rheumatologic diseases is then tailored to the patient's needs and lifestyle.

\section{Tocilizumab \\ Mechanism}

Tocilizumab (TCZ; trade names Actemra, Roactemra) is a recombinant monoclonal IgG1 anti-human IL-6 receptor (IL-6R) antibody (Table 1) [1]. IL-6 binds to either membrane-bound or soluble IL-6R, and this complex in turn binds to the 130 gp signal transducer. This process enhances the inflammatory cascade, inducing angiogenesis and amplifying the activity of adhesion molecules and the activation of osteoclasts [2,3]. IL-6 is also responsible for activating both $\mathrm{T}$ and $\mathrm{B}$ helper cells, and is involved in B-cell differentiation, thus by blocking IL-6, the inflammatory response is decreased [2].

In patients with RA, a high level of IL-6 is present in the blood and in the synovium of involved joints. In an animal study, injecting TCZ into the inflamed joints reduced the swelling and the inflammatory response $[2,4]$.

\section{Indications and dosage}

TCZ is indicated for the treatment of RA following an inadequate response or treatment failure with DMARDs or TNF alpha antagonists (anti-TNF alpha drugs). It is also indicated as first-line therapy for patients with severe systemic juvenile idiopathic arthritis (SJIA) and for Castleman's disease (Table 1).

The recommended dose of TCZ is $8 \mathrm{mg} / \mathrm{kg}$ every 4 weeks. The drug was approved for RA in January 2010 in the USA, but the US recommendations are for a starting dose of $4 \mathrm{mg} / \mathrm{kg}$ once every 4 weeks, followed by an increase to $8 \mathrm{mg} / \mathrm{kg}$ depending on clinical response [5,6]. The route of administration is IV, with the dose of 4 to $8 \mathrm{mg} / \mathrm{kg}$ IV administered as a single infusion every 4 weeks for RA and $12 \mathrm{mg} / \mathrm{kg}$ or $8 \mathrm{mg} / \mathrm{kg}$ IV (depending on body weight) for SJIA [6]. Within an RA population, in Disease Activity Score(DAS) remission rate was $55.3 \%$ for patients treated for 5 years on monotherapy [7].

\section{Efficacy}

A meta-analysis examined published articles on doubleblind, randomized, placebo-controlled trials that indirectly compared TCZ with one or more of the following

Table 1 Update on biologic therapy in autoimmune diseases

\begin{tabular}{|c|c|c|}
\hline Drug (trade name) & Mechanism of action & Indications \\
\hline Tocilizumab (Actemra) & $\begin{array}{l}\text { Recombinant monoclonal lgG1 anti-human interleukin } \\
\text { 6-receptor antibody [1] }\end{array}$ & $\begin{array}{l}\text { RA after treatment failure with anti-TNF, } \\
\text { SJIA }{ }^{1}[5-7]\end{array}$ \\
\hline Rituximab (Rituxan) & $\begin{array}{l}\text { Chimeric human monoclonal antibody against the } \\
\text { CD20 protein [12] }\end{array}$ & $\begin{array}{l}\text { RA, }{ }^{1} \text { WG, MPA. Off-label use: ITP, refractory } \\
\text { pemphigus vulgaris [13-23] }\end{array}$ \\
\hline Ofatumumab (Arzerra) & $\begin{array}{l}\text { Fully human monoclonal antibody directed against } \\
\text { membrane proximal epitope on the CD20 molecule [25] }\end{array}$ & $\mathrm{RA}^{1}[24,25]$ \\
\hline Belimumab (Benlysta) & $\begin{array}{l}\text { Human monoclonal immunoglobulin lgG1 gamma, } \\
\text { which binds to and inhibits the soluble form of the } \\
\text { BLyS protein }[27,28]\end{array}$ & $\operatorname{SLE}^{1}[26,27]$ \\
\hline Epratuzumab (Lymphocide) & $\begin{array}{l}\text { IgG1 monoclonal antibody directed against the CD22 } \\
\text { molecule }[29,30]\end{array}$ & SLE, Sjögren's syndrome [28-30] \\
\hline Abatacept (Orencia) & $\begin{array}{l}\text { CTLA-4 lgG1 binding to CD80/86 on antigen-presenting } \\
\text { cells inhibiting the co-stimulation of CD28 on the } T \\
\text { cells [32] }\end{array}$ & $\begin{array}{l}\text { RA, }{ }^{1} J A^{1} \text { SLE - discoid, serositis and arthritis } \\
\text { manifestations [31-35] }\end{array}$ \\
\hline Golimumab (Simponi) & $\begin{array}{l}\text { IgG1 monoclonal antibody, acting on TNF-a, both } \\
\text { soluble and membrane-bound [37] }\end{array}$ & $\mathrm{RA}^{1}{ }^{1} \mathrm{PSA}^{1}{ }^{1} \mathrm{AS}^{1}[36-40]$ \\
\hline Certolizumab (Cimzia) & $\begin{array}{l}\text { Pegylated humanized antibody Fab' fragment of the } \\
\text { TNF-a monoclonal antibody [42] }\end{array}$ & $\mathrm{RA}^{1}[41,42]$ \\
\hline Sifalimumab & An anti-IFN-a monoclonal antibody [44] & Phase III trial $[43,44]$ \\
\hline Intravenous immunoglobulin & $\begin{array}{l}\text { Pool of immunoglobulins from healthy individuals. Many } \\
\text { mechanisms involved }[48,49]\end{array}$ & SLE, systemic sclerosis, vasculitis $[49,50]$ \\
\hline $\begin{array}{l}\text { Anakinra (Kineret), canakinumab (llaris), } \\
\text { rilonocept (Arcalyst) }\end{array}$ & All three are interleukin-1 blockers & RA, CAPS [45-47] \\
\hline
\end{tabular}

${ }^{1}$ Approved by the US Food and Drugs Administration. Abbreviations: AS, ankylosing spondylitis; BLyS, B-lymphocyte stimulator; CAPS, cryopyrin-associated periodic syndrome; CTLA, cytotoxic T lymphocyte-associated; JIA, juvenile idiopathic arthritis; MPA, microscopic polyangiitis; PsA, psoriatic arthritis; RA, rheumatoid arthritis; SLE, systemic lupus erythematosus; TNF, tumor necrosis factor; Wegener's granulomatosis. 
biologics: abatacept, rituximab, or anti-TNF-alpha blockers (etanercept, infliximab, and adalimumab), in patients with inadequate response to DMARDs and/or antiTNF-alpha blockers. TCZ was non-inferior compared with the other biologic therapies according to the American College of Rheumatology (ACR) criteria for a $20 \%$ (ACR20) or $50 \%$ (ACR50) improvement, and was superior for a 70\% improvement (ACR70) [8]. Furthermore, the response to TCZ occurred early, soon after the first infusion [1].

Monotherapy with TCZ for 52 weeks resulted in significantly reduced radiographic change (total Sharp score) compared with DMARDs [2]. In a 24-week study comparing TCZ and methotrexate (MTX), TCZ was found to be non-inferior to MTX in the first week and superior to MTX in the second week in the intention-to -treat group, as measured by ACR20 [3]. Several other studies comparing monotherapy of MTX with that of TCZ have also shown superiority of TCZ [3,9]. In a study of 1,196 patients with RA who responded partially to MTX, treatment with TCZ led to suppression in radiographic progression and improvement in physical function [9]. Other studies reported response to TCZ in patients with RA who failed to respond to anti-TNF -alpha blockers [9].

\section{Adverse effects and safety}

Favorable safety results for TCZ were reported for both short-term and long-term treatment of moderate to severe RA. In one meta-analysis, TCZ was well tolerated for more than 2.4 years of treatment, and the AEs were less severe compared with other biologic therapies [8]. In a 24-week study of 286 patients with RA, 66.1\% experienced AEs related to the drug, which were mild to moderate and transient. A small number of patients experienced serious AEs, which were predominantly infections [1].

In a study integrating the three phases of TCZ safety, the AEs were similar to the other treatment groups (DMARDs or anti-TNF-alpha). The most common AEs were infections, mostly of the upper respiratory tract (URTI) and gastrointestinal (GI) tract [10]. More severe AEs included cardiac events, serious infections, solidorgan malignancies, non-melanoma skin tumors, and hematological disturbances [10]. Higher rates of serious infections were related to previous anti-TNF-alpha treatment. The most common infections were pneumonia, gastroenteritis, and urinary-tract infections [10]. Some patients were diagnosed with $\mathrm{TB}$ despite being screened before treatment in accordance with the guidelines. Higher doses of TCZ $(8 \mathrm{mg} / \mathrm{kg})$ were associated with higher risks for infection, but rates were still similar to those encountered with DMARDs or anti-TNF-alpha blockers [10]. GI perforation occurred in 16 patients (predominantly women) exposed to TCZ in the phase III trials, with 11 of them developing diverticuli [10]. Some patients developed a significant increase in liver-function tests, indicating liver dysfunction; a dose reduction was sufficient for the continuation of the study. Only $2.3 \%$ of TCZ-exposed patients had to discontinue treatment because of liver abnormalities [10]. There was a reduction in neutrophil count in patients receiving TCZ, which stabilized after 2 weeks of therapy. Some patients developed grade 4 neutropenia, but the neutrophil count normalized after discontinuation of therapy [10].

In other studies of monotherapy with TCZ, the AEs reported were nasopharyngitis, GI symptoms, and infections. There was no difference in the incidence of AEs with TCZ compared with anti- TNF-alpha blockers [3]. TCZ was associated with increases in cholesterol levels and in the ratios of low-density lipoprotein (LDL) to high-density lipoprotein (HDL) cholesterol, and of total to HDL cholesterol [11].

In conclusion, TCZ is beneficial and safe for treatment of RA in cases of non-response to anti-TNF-alpha therapy or when anti-TNF-alpha therapy is contraindicated.

\section{Rituximab \\ Mechanism}

Rituximab (trade names Rituxan, Mabthera) is a chimeric human monoclonal antibody against the CD20 protein found on naive, mature, and memory B cells. Rituximab depletes the B-cell population via apoptosis, cellular cytotoxicity, and complement activation. In a number of studies measuring markers for immature B cells, memory $\mathrm{B}$ cells, and pre-B cell colony-enhancing factor (visfatin), B-cell depletion occures after treatment with rituximab [12]. In addition, rituximab affects the interferon (IFN) I response genes. In patients with RA responding to rituximab treatment, expression of IFN response genes (RSAD2,IFNI44L, HERC5, LY6E, Mx1) increased, whereas the non-responding patients had limited or no IFN geneexpression activity (Table 1) [12].

\section{Indications and dosage}

For autoimmune diseases, the only indication for which rituximab is approved by the Food and Drugs Administration (FDA) is active RA unresponsive to DMARDs and anti-TNF-alpha agents. Rituximab is beneficial for other off-label indications in patients with autoimmune disease (such as SLE) and Castleman's disease (Table 1).

The most popular protocol for RA is IV infusion of $1000 \mathrm{mg} / \mathrm{m}^{2}$ on days 1 and 15 in combination with MTX. Subsequent courses may be administered every 24 weeks (based on clinical evaluation), and if necessary, may be repeated, but no sooner than every 16 weeks. For patients with RA, pre-medication with IV methylprednisolone $100 \mathrm{mg}$ (or equivalent) is recommended, 30 minutes before 
each dose of rituximab [13]. For granulomatosis with polyangiitis (GP) (previously Wegener's granulomatosis), the protocol is different: IV infusion with $375 \mathrm{mg} / \mathrm{m}^{2}$ once weekly for four doses (in combination with IV methylprednisolone for 1 to 3 days followed by daily prednisone). The protocol for microscopic polyangiitis (MPA) is similar to that of GP [14].

Rituximab was evaluated for chronic immune thrombocytopenic purpura (ITP) in a multi-center phase II study of 60 patients, who received an IV infusion of $375 \mathrm{mg} / \mathrm{m}^{2}$ once weekly for 4 doses; $40 \%$ of patients achieved a steady platelet level [15]. A few studies also suggested that low-dose treatment with $100 \mathrm{mg} / \mathrm{m}^{2}$, either alone or in combination with steroids would suffice and result in fewer AEs; however, further data on this dose are lacking [15].

For refractory pemphigus vulgaris (PV), the recommended treatment is IV infusion of $375 \mathrm{mg} / \mathrm{m}^{2}$ rituximab once weekly in weeks 1, 2, and 3 of a 4-week cycle, which is repeated for one additional cycle, followed by one dose per month for 4 months (total of ten doses in 6 months) [16]. The initial infusion should be started at $50 \mathrm{mg} /$ hour, and if there is no reaction, the rate should be increased by $50 \mathrm{mg}$ every 30 minutes (100 mg/hour).

\section{Efficacy}

Several studies suggest that rituximab may be beneficial for the treatment of SyS [17]. In a study of eight patients with SyS, the B-cell infiltrate was depleted in the skin after rituximab infusion, signifying that the drug might be a possible therapy for skin fibrosis [17]. Another study of 15 patients with SyS also showed histological improvement in the skin after rituximab therapy [17].

In a study of 257 patients with SLE treated with rituximab and prednisone, disease activity was not significantly improved compared with placebo. However, in a subgroup analysis of African American and Hispanic patients, there was a significant benefit for rituximab therapy. Furthermore, in open trials for long-term treatment, rituximab was found to be superior [18]. The lack of efficacy in the overall trial could be associated with the clinical set-up of the trial, inclusion of too many subsets, or non-stratification of patients positive or negative for anti-double-stranded DNA antibodies [19].

A case series indicated that rituximab might be beneficial in hemolytic anemia, thrombocytopenia, and arthritisrelated SLE [20].

In a study of 646 patients with RA who had treatment failure with anti-TNF-alpha blockers, follow-up at 6 months after therapy with rituximab resulted in a good clinical response and even remission of the disease [21].

In the SUNRISE (Study of Retreatment with Rituximab in Patients with Rheumatoid Arthritis Receiving Background Methotrexate) trial, 559 patients with RA with inadequate response to one or more TNF-alpha inhibitors were given two treatment cycles of rituximab to assess the efficacy and safety profile of the drug. Of the total 559 patients in the study, 475 patients received the second cycle of therapy, with a significant response compared with the placebo group, as measured by the ACR20 [13].

In a study of 42 patients with severe PV, rituximab was administered as monotherapy, inducing remission in 36 patients for periods of 8 to 64 months. In those patients requiring an additional dose, the safety profile remained good [16].

\section{Adverse effects and safety}

One of the AEs associated with rituximab is an infusion reaction, characterized by fever, chills, rash, swelling (of hands, feet, and face), bronchospasm, and hypotension. In most cases, the reaction is immediate (30 minutes to 2 hours), usually during the first infusion, but is less severe with subsequent infusions. Pretreatment with acetaminophen and an anti-histamine is recommended to prevent this infusion reaction. If the infusion reaction occurs, the infusion rate should be decreased or discontinued. Additional treatment with steroids may also be warranted. Rituximab treatment requires monitoring of several AEs, including infections, TB, and lymphoma [22]. It is contraindicated in the case of pregnancy and breastfeeding, active infections, live vaccination, severe congestive heart failure, a history of demyelinating disease, and a 5-year history of non-lymphoproliferative cancer [23].

In a meta-analysis assessing the safety of rituximab, including long-term therapy, 123 of 2,578 patients with RA withdrew because of malignancy, infection, a severe infusion reaction, or cardiac event [22]. Most AEs occurred during the first course of therapy. The incidence of malignancies was not increased in patients with RA treated with rituximab [22].

Rituximab causes a decrease in gammaglobulin concentrations, depending on the cumulative dose; however, this does not seem to lead to a higher risk for severe infection [23]. A few cases of progressive multifocal leukoencephalopathy (PML) were reported in some patients after rituximab therapy [22].

\section{Ofatumumab \\ Mechanism}

Ofatumumab (trade name Arzerra) is a fully human monoclonal antibody directed against the membrane proximal epitope on the CD20 molecule (Table 1) [24-25].

\section{Indications and dosage}

Ofatumumab is indicated for the treatment of chronic lymphocytic leukemia. Owing to its B-cell-suppressing effect, it is also used in the USA and Europe as an off-label 
treatment for patients with RA who have failed MTX therapy (Table 1). In a combined phase I and II study, patients received three escalating doses of ofatumumab (300, 700, and $1000 \mathrm{mg}$ ), with each dose given as two separate IV administrations with 2 weeks between them, over a period of 24 weeks [25]. Prior to administration, all patients in the high-dose groups received premedication with acetaminophen, anti-histamine, and glucocorticoids.

The recommended protocol for maximum efficacy and safety is IV administration of $700 \mathrm{mg}$ over 4 hours with appropriate premedication, repeated every 2 weeks $[24,25]$.

\section{Efficacy}

Two studies reported efficacy of ofatumumab compared with placebo or MTX in patients previously treated with DMARDs or biologic therapies; all such therapies were discontinued prior to study entry $[24,25]$. In one study, comparing the efficacy of ofatumumab (three different dose groups) with patients treated with placebo or MTX, significantly higher rates of ACR20 were seen in the ofatumumab groups compared with the placebo group. In addition, the efficacy was dose-dependent, as assessed by the ACR20 and the circulating B-cell population [24].

In another multi-center double-blind RCT of biologic therapies in naive patients with RA, ofatumumab $700 \mathrm{mg}$ was compared with placebo, and a significantly higher rate of improvement as measured by ACR20 was noted in the ofatumumab group [25]. No significant differences were noted between seronegative and seropositive patients in this study [25].

\section{Adverse effects and safety}

In a study comparing the safety of ofatumumab (three different dose groups), the main AEs were related to infusion reaction, which was mild to moderate and occurred mainly with the first and second administrations [24]. However, after 24 weeks of treatment, a significant number of AEs occurred in the highest-dose (1000 mg) group [24]. No difference in infections was noted between the different dosage groups and the placebo [24]. Other AEs included rash, dyspnea, rhinitis, nausea, pruritus, URT infections, headaches, fatigue, flushing, hypertension, and diarrhea.

In another double-blind multi-center study, the most common reactions were urticaria and rash on the day of the first infusion. Most of the reactions were mild to moderate, and severe AEs were infrequent [25]. No case of PML was reported [25].

\section{Belimumab}

\section{Mechanism}

The BLyS protein is a member of the superfamily of TNFs. It inhibits B cell apoptosis and stimulates the differentiation of $\mathrm{B}$ cells into immunoglobulin-producing plasma cells. Belimumab (trade name (Benlysta) is a human monoclonal immunoglobulin (IgG1 $\gamma$ ), which binds to and inhibits the soluble form of the BLyS protein [26,27] (Table 1).

\section{Indications and dosage}

Belimumab is approved by the FDA for the treatment of mild to moderate SLE, and is presently not indicated for active LE nephritis or neuropsychiatric involvement (Table 1) [26,27]. It is given by slow IV infusion over 1 hour at a recommended dose of $10 \mathrm{mg} / \mathrm{kg}$ at 2-week intervals for three cycles, then once every 4 weeks [26,27].

\section{Efficacy}

In a phase II trial, there was a significant effect of belimumab after 52 weeks of treatment and a steroidsparing effect. However, no improvement in the SLE responder index (SRI), which incorporates disease activity scores to compile a single score, disease activity score was significant in SLE patients with severe active disease [26]. In the phase III clinical trials assessed using the SRI, a significant improvement was seen in both the $1 \mathrm{mg} / \mathrm{kg}$ and the $10 \mathrm{mg} / \mathrm{kg}$ groups compared with the placebo group [28]. Significant changes were also reported in the SELENA-SLEDAI (Safety of Estrogens in Lupus Erythematosus National Assessment-Systemic Lupus Erythematosus Disease Activity Index) trial, with noninferiority of belimumab compared with placebo, as measured by the Physician's Global Assessment (PGA) [26].

\section{Adverse effects and safety}

AEs associated with belimumab treatment include nausea, diarrhea, headaches, and URT infections. Less common side effects are fever, cystitis, leucopenia, infusion reaction, and severe infections. Studies have shown that the number of AEs associated with belimumab were similar to that in the placebo group, and that the severity and number of AEs did not increase in the high-dose $(10 \mathrm{mg} / \mathrm{kg})$ group compared with the low-dose $(1 \mathrm{mg} / \mathrm{kg})$ group [26,27].

\section{Epratuzumab \\ Mechanism}

Epratuzumab is an IgG1 monoclonal antibody directed against the CD22 molecule. CD22 is a B-cell-specific transmembrane sialoglycoprotein that inhibits the B-cell receptor complex, causing early apoptosis and thus shortening the cell's life span (Table 1) [28,29].

\section{Indications and dosage}

The therapeutic dose of epratuzumab is $360 \mathrm{mg} / \mathrm{m}^{2} \mathrm{IV}$ over 1 hour every 2 weeks for up to four cycles. It is recommended that acetaminophen and anti-histamine should be administered prior to infusion to minimize infusion reaction [30]. Owing to its anti-CD22 targeting 
activity, epratuzumab is indicated for the treatment of SLE and Sjögren's syndrome (Table 1) [30].

\section{Efficacy}

Although epratuzumab has not received regulatory approval for SLE and Sjogren's syndrome, several studies have assessed the drug for these two conditions (excluding patients who were previously treated with rituximab). In a study measuring scores on the British Isles Lupus Assessment Group (BILAG) scale during a follow-up of 6 months, all patients had a decrease in disease activity of more than $50 \%$ [30]. In a larger study of 227 patients with moderate to severe SLE, comparing doses of $600,800,2,400$, or $3,600 \mathrm{mg}$ epratuzumab with placebo for 12 weeks, all epratuzumab groups had a significant response as measured by BILAG score [29]. In a different study of patients with Sjögren's syndrome, $67 \%$ of patients responded to 6 months of epratuzumab therapy, indicating regeneration of glandular tissue [30].

\section{Adverse effects and safety}

In the phase II trial of 227 patients described above, there was no significant difference in AEs between the placebo group and any of the epratuzumab groups [30].

In the study of patients with SLE, most of the AEs were minor, and included nausea, fatigue, general pain, and infusion reaction [30]. Patients with Sjögren's syndrome had more severe AEs during the infusion, including swelling of the nasal mucosa and increased pressure in the glottis [30].

\section{Abatacept}

Mechanism

$\mathrm{T}$ cells play a major role in the pathogenesis of RA. Co-activation of CD28 with the antigen-presenting cell (APC) protein $\mathrm{CD} 80 / 86$ results in release of inflammatory cytokines. Cytotoxic T lymphocyte-associated (CTLA)-4 is a protein with a high affinity to CD80/86, which inhibits T-cell activation by blocking the CD28 binding. Abatacept (trade name Orencia) is a CTLA-4 IgG1 that binds to CD80/86 on APCs, inhibiting the co-stimulation of CD28 on T cells (Table 1) [31].

\section{Indications and dosage}

Abatacept is approved by the FDA for the treatment of RA that is non-responsive to DMARDs and anti-TNF-alpha blockers, and for JIA (Table 1). For RA treatment, the dose is based on body weight, with a dose of approximately $10 \mathrm{mg} / \mathrm{kg}$ (patients weighing less than $60 \mathrm{~kg}$ receive $500 \mathrm{mg}$; those weighing 60 to $100 \mathrm{~kg}$ received $750 \mathrm{mg}$, and those weighing more than $100 \mathrm{~kg}$ receive $1000 \mathrm{mg}$ ). The initial IV dose can be repeated by additional doses after 2 and 4 weeks, with further doses every 4 weeks after that. Another treatment option after the initial IV dose is to administer a subcutaneous (SC) injection of $125 \mathrm{mg}$ at 24 hours after the first infusion, repeated by weekly SC injections of $125 \mathrm{mg}$ [31,32].

For JIA, the route of administration is also IV, and the dose is based on body weight and age (children 6 years over weighing less than $75 \mathrm{~kg}$ receive $10 \mathrm{mg} / \mathrm{kg}$, those weighing 75 to $100 \mathrm{~kg}$ receive $750 \mathrm{mg}$, and those weighing over $100 \mathrm{~kg}$ receive $1000 \mathrm{mg}$ ).

The same protocol as described above for patients with RA was used in a multi-center double-blind placebo-controlled study of 180 patients with SLE with discoid rash, serositis, or polyarthritis. The results of the study suggest some abatacept efficacy in patients with non-life-threatening manifestations of SLE, but due to safety issues, further assessment.is warranted [32].

\section{Efficacy}

In a meta-analysis comparing phase II and III studies including an extension phase, improvement in disease activity in patients with RA, as measured by the ACR score, was reported with combined therapy with abatacept and DMARDs within 6 months. This included patients who had not responded to prior anti-TNF-alpha therapy. There was an average improvement of 50\% in ACR20 in the abatacept group, compared with $30 \%$ in the placebo group. Similar results were found for ACR50 and ACR70 in the abatacept group compared with the placebo group and with other treatment groups [33]. In a long-term study comparing abatacept with placebo (with background therapy for both groups of a steady dose of MTX), the response to abatacept was superior and was maintained for 3 years including physical function scores [34]. Evaluation of radiographic changes identified a reduction in bone erosion scores (Genant-modified Sharp scoring method) every year within the 3-year follow-up, and $40 \%$ of patients had no radiographic progression after 3 years [35].

In another study of 180 patients with SLE, abatacept had a steroid-sparing effect and resulted in a lower rate of flares. This effect was predominant in the lupus patients with polyarthritis [32]. Furthermore, in the abatacept group, significant improvement in well being was reported by the HAQ (Health Assessment Questionnaire) [32].

\section{Adverse effects and safety}

The main AEs caused by abatacept are infections, URT symptoms, nausea, headache, infusion reaction, fever, hypertension, and back and limb pain.

In a study of long-term safety, $96 \%$ of patients experienced AEs; however, most of them were mild to moderate and mostly related to infections. No significant differences in AEs were noted when the abatacept group 
and the placebo group (receiving DMARDs only) were compared [35].

\section{Novel anti-TNF-a blockers \\ Golimumab}

Mechanism Golimumab (trade name Simponi) is a fully human monoclonal IgG1 antibody, acting on both soluble and membrane-bound TNF- $\alpha$ (Table 1) [36].

Indications and dosage Golimumab is approved by the FDA for RA, psoriatic arthritis (PsA), and ankylosing spondylitis (AS) (Table 1) [37-40]. The indicated dose for all three diseases is $50 \mathrm{mg}$ monthly by $\mathrm{SC}$ injection. For RA, golimumab is administered in combination with MTX; for PsA it may be administered alone or with MTX; and for AS, it may be administered alone [40].

In a study comparing treatment groups given doses of 50 or $100 \mathrm{mg}$ golimumab SC, no significant difference occurred between the two groups. The lower dosage is recommended by the FDA [37].

Efficacy In a study of patients with AS comparing different doses of golimumab with placebo for 24 weeks, a significant improvement was found in the AS International Working Group criteria (20\% improvement; ASAS20) for all golimumab groups compared with the placebo group [37]. In a similar study in patients with PsA, using two different doses of golimumab; a significant improvement was encountereed in both golimumab groups compared with placebo [37]. Furthermore, there was a significant improvement in both enthesitis and Dactylitis Severity Score [37].

In a study of patients with RA who were not responsive to MTX, (GO-FORWARD study [38]) the efficacy of MTX plus placebo, MTX plus golimumab $50 \mathrm{mg}$, MTX plus golilumab $100 \mathrm{mg}$, or golimumab $100 \mathrm{mg}$ plus placebo, were compared. The most significant results were seen in the MTX plus golimumab groups (both doses) compared with MTX alone. However, a higher incidence of AEs was noted in the golilumab $100 \mathrm{mg}$ group [38]. In another study (GO-BEFORE study [39]), using the same protocol as the previous study but in MTX naïve patients with RA, a significant response was seen with golimumab as measured by ACR70, ACR90, 28-item Disease Activity Score (DAS28), and HAQ [39]. The primary outcome of ACR50 was not achieved, which could be attributable to lower disease activity in these patients compared with patients receiving other biologic therapy-based studies, as well as to group size and possibly C-reactive protein levels. However, the modified intention-to-treat analysis of the primary endpoint and other pre-specified efficacy measures did show efficacy in both the golimumab plus MTX groups in these patients [39].
Adverse effects and safety The main AEs are infections (mostly of the URT) and nausea. Additional AEs include hypertension, abnormal liver function (patients with latent $\mathrm{TB}$ were required to take prophylactic treatment, resulting in greater liver abnormalities), paresthesia, dizziness, constipation, local skin reaction, and some cases of malignancy (basal and squamous cell carcinomas, and prostate, lung, and breast cancers) were reported [37-40].

In studies performed to assess golimumab safety, more infections occurred in patients receiving golimumab compared with those receiving placebo [36-39]. In the study on patients with PsA, those who received $100 \mathrm{mg}$ golilumab had significantly higher rates of infections than those who received $50 \mathrm{mg}$, but these were mainly minor infections involving the URT [38].

\section{Certolizumab pegol}

Mechanism Certolizumab (trade name Cimzia) is a pegylated Fab fragment of a humanized TNF-alpha monoclonal antibody, which binds to and inhibits TNF-alpha. The pegylation extends the half-life of the antibody, and the missing $\mathrm{Fc}$ fragment reduces the risk of cytotoxicity (Table 1) [41,42].

Indications and dosage Certolizumab is approved by the FDA for the treatment of active RA disease (Table 1), given as SC injection of $400 \mathrm{mg}$ every 2 weeks for three consecutive cycles, followed by maintenance therapy of $200 \mathrm{mg}$ SC every 2 weeks.

Efficacy In a study of patients diagnosed with RA for no less than 6 months and no more than 15 years, who had not received any biologic therapy for 6 months before the beginning of the study, but had responded to antiTNF-alpha blockers in the past, were enrolled. The first group was treated with MTX plus placebo and the second with MTX plus certolizumab. ACR20 response, physical improvement, and reduction in radiographic progression were achieved more rapidly in the certolizumab group compared with the placebo group over a 1-year period [41].

In a different study of patients with RA who had experienced treatment failure with DMARDs, a significant ACR20 response of up to 50\% was accomplished with certolizumab monotherapy. Similar improvements were also encountered for disease activity, physical function, and arthritic pain [42].

Adverse effects and safety Other than the AEs already recognized for treatment with TNF-alpha blockers, a higher incidence of serious infections was noted with certolizumab [42]; these AEs occurred with the lower dose of $200 \mathrm{mg}$ but not the higher dose of $400 \mathrm{mg}$ [42]. 
In a safety study of patients with RA, the AEs reported for certolizumab were headache, nasopharyngitis, diarrhea, and sinusitis [42]. A significantly higher incidence of serious AEs were detected in patients receiving certolizumab, and these included bacterial arthritis, salmonella arthritis, ischemic stroke, menorrhagia, mastitis, and increases in blood creatinine and urea levels [42]. There were no fatalities or cases of druginduced SLE [42].

\section{Sifalimumab}

Sifalimumab is an anti-interferon (IFN)-alpha monoclonal antibody. Patients with SLE carry a typical type I IFN signature. Compared with normal controls, overexpression of B cell activation factor (BAFF) mRNA in whole blood characterizes patients with SLE. The effect of anti-IFN -alpha antibody was examined using B lymphocyte stimulator/BAFF, and PCR identified suppression of BAFF mRNA (Table 1) [43,44].

The safety of sifalimumab was evaluated in a phase I trial of SLE. There were no drug-related AEs and no increase in viral infections. In the trial, there was improvement in disease activity with sifalimumab compared with placebo [44], and the drug is currently in phase III trials [20].

\section{Interleukin-1 inhibitors}

Anakinra (trade name Kineret) is approved by the FDA for treatment of RA. Recently, other IL-1 blockers became available. Two of these are indicated for the treatment of disorders collectively known as cryopyrin-associated periodic syndromes (CAPS).

Canakinumab (trade name Ilaris) is specifically indicated in adults and in children aged 4 years and older for the treatment of CAPS, including familial cold autoinflammatory syndrome (FCAS) and Muckle-Wells syndrome (MWS) (Table 1). For adults, it is administered via SC injection at a dose of $150 \mathrm{mg}$ every 8 weeks. Canakinumab is beneficial, safe, and leads to a reduction in serum amyloid A (SAA) and C-reactive protein (CRP) levels. The associated AEs include infections [45].

Rilonacept (trade name Arcalyst) is an IL-1 blocker that is also indicated for the treatment of CAPS, including FCAS and MWS, in adults and in children aged 12 years and older. Rilonacept (160 mg SC weekly for adults and $2.2 \mathrm{mg} / \mathrm{kg}$ or up to $160 \mathrm{mg}$ for children) maintained long-term efficacy and safety in an extension study of 72 to 96 weeks, including normalization of the inflammatory markers CRP and SAA. AEs were mild to moderate, and included injection site reactions and URTI [46]. IL-1 inhibitors are currently under investigation for the treatment of acute gout flares [47].

\section{Intravenous immunoglobulin therapy Mechanisms}

IVIG is a well established therapy for immunodeficiency diseases, and is beneficial for autoimmune diseases [48]. The immunoglobulins are derived from a pool of thousands of healthy donors, containing antibodies to both self and foreign antigens.

Several mechanisms of action are suggested for immunoglobulins, and they influence the immune system at many levels. IVIG has a direct neutralization effect on pathogenic antibodies, $\mathrm{B}$ and $\mathrm{T}$ cells, and macrophage regulation. It inhibits the differentiation and maturation of dendritic cells, prevents the presentation of self antigens, modulates IL-1 receptor antagonists, and inhibits BLyS activity (Table 1) [49].

\section{Dosage protocols}

The characteristics of the various IVIG products are not discussed here, but can be readily found online (http:// www.medprorx.com/ref_ivig_drug.html). Different IVIG protocols are in use, depending on the disease. In systemic autoimmune diseases such as SLE, a high-dose protocol is often used, consisting of $2 \mathrm{~g} / \mathrm{kg}$ divided over 5 days. This is repeated every 4 weeks, a period that allows the immunoglobulin level in the serum to return to normal. The cycle repeats every month, usually for up to 6 months, and then every 2 to 3 months if required. Long term, therapy remains beneficial [50]. To reduce AEs, a single dose of hydrocortisone 100 to $200 \mathrm{mg}$ should be administered on day 1 before initiation of the IVIG therapy. Treatment with a single dose of low-molecular -weight (LMW) heparin before IVIG initiation may prevent possible thromboembolic AEs [51]. Low-dose IVIG therapy ( $400 \mathrm{mg} / \mathrm{kg}$ over 1 day every 3 to 4 weeks) is beneficial for organ-specific disease, predominantly neurological conditions [50]. It may also be useful for some cases of mild to moderate SLE [52].

\section{Efficacy}

IVIG may be an adjunctive therapy for patients with SLE who are refractory to conventional therapies. It may also be an option for young women who do not wish to risk the problems of disfigurement or sterility associated with conventional immunosuppressive therapies. Based on the various case reports and case series, it appears that high-dose IVIG is beneficial for moderate to severe SLE. It is beneficial for the treatment of serositis, cardiopulmonary disease, hematological conditions, diffuse neuropsychiatric disease, and lupus nephritis [53-55]. In patients with SLE, IVIG has a steroid-sparing effect [56]. High-dose IVIG was beneficial for SLE, and led to a decrease in various scores of disease activity. IVIG may be useful for recalcitrant cases of organ-specific cutaneous LE including discoid LE and subacute cutaneous LE. In many cases, 
patients received short-term therapy with moderate or low doses [48]. IVIG causes a serological improvement including a decrease in antibody titer levels and an increase in complement levels [49].

IVIG may be beneficial as off-label for a number of other autoimmune diseases including Sjogren's syndrome, polyneuropathy, severe PV, Still's disease, and relapsing anti-neutrophil cytoplasmic antibody-associated vasculitis [49]. Low-dose IVIG is beneficial for Guillain-Barré syndrome, Lambert-Eaton syndrome, refractory myasthenia gravis, refractory multiple sclerosis, multifocal motor neuropathy, chronic inflammatory demyelination polyneuropathy, dermatomyositis, and stiff person syndrome [48]. In addition, polyneuropathy in SLE and vasculitis respond well to IVIG therapy [57]. Other diseases in which IVIG is used include refractory uveitis, Graves' disease, and ocular involvement in Behcet's disease [48].

\section{Adverse effects and safety}

IVIG is usually associated with mild and transient AEs. The common mild AEs include arthralgia, myalgia, weakness, abdominal pain, diarrhea, chills, dizziness, drowsiness, fatigue, fever, headache, and changes in blood pressure or heart rate [50]. The more severe AEs include anaphylactic reaction, thromboembolic events, neutropenia, pancytopenia, autoimmune hemolytic anemia, renal failure with acute tubular necrosis, asthma exacerbation, hepatic dysfunction, seizures, acute respiratory distress syndrome, and aseptic meningitis [55,58]. AEs occurring with the first course may return with further courses [50], and do not usually worsen with long-term IVIG therapy [50].

Special attention is advised when treating patients with pro-thrombotic risk and those with renal failure or who are at risk of renal tubular injury (dehydration, renal disease, diabetes). In cases where there is a high risk of thromboembolic event, LMW heparin is to be administered before initiation of the IVIG course. IVIG is contraindicated in patients with IgA deficiency [49].

\section{Immunogenicity of biologic therapies}

Biologic agents are engineered molecular targeted therapies, which include antibodies and receptor blockers. Antibodies may be chimeric or fully human. As a result, patients may develop immunogenicity to these agents, characterized as development of antibodies to the biologic agent itself, or the development of pathogenic autoantibodies that can lead in some cases to the development of another autoimmune disease. Antibodies targeted against the biologic therapy, termed human anti-chimeric antibodies (HACA), may lead to a decrease in the efficacy of the medication, hence a DMARD (usually MTX) is often recommended as co-treatment to counteract the increased levels of HACA. With the availability of fully human antibody biologic agents, the development of
HACA may be negligible. Although the development of antinuclear antibodies and anti-double-stranded DNA antibodies have been reported secondary to biologic treatment, the development of frank SLE is infrequent. However, drug-induced SLE secondary to biologic therapies is not a mild disease, as usually seen for other medications, but rather a severe systemic disease with renal impairment [59].

\section{Immunogenicity of specific drugs}

The newly developed drugs may not cause significant immunogenicity effects. Several studies of TCZ showed that the development of anti-chimeric antibodies had no significant clinical effect [5].

In a study of 130 patients receiving ofatumumab, no patients developed drug antibodies [25], and in a study of belimumab treatment, negative seroconversion occurred significantly more frequently in the belimumab treatment group [27].

In a trial comparing the immunogenicity of epratuzumab with rituximab, fewer anti-chimeric antibodies developed compared to epratuzumab [29]. In a study of 339 patients receiving abatacept, only two patients developed drug-related antibodies, which was not statistically significant [32]. In the GO-FORWARD study of golimumab, only $2.1 \%$ of patients with RA developed drug antibodies [39].

In a phase I multi-center double-blind trial of 33 patients treated with sifalimumab, there were no anti-sifalimumab antibodies detected prior to administration or at several points during the study [44]. In a study of 619 patients treated with certolizumab, only $5.1 \%$ of patients developed anti-drug antibodies, which was not statistically significant [42].

\section{Discussion}

We reviewed the literature on new biologic therapies that have recently become available and how they are used to treat various autoimmune diseases. Some of these are new drugs in known classes (TNF alpha blockers and B cell modulators), whereas others are of a new class (BLyS inhibitors, IFN I inhibitors, IL-1 inhibitors). The AEs are similar for all the biologic therapies reviewed, with the severe AEs including serious infections. TB recurrence has been virtually eradicated due to the accepted screening recommendations before starting biologic therapy.

It is advantageous to have a range of effective biologic drugs available for patients with severe or resistant disease. Severe disease can include involvement of vital systems, persistent disease despite conventional therapy or even persistent and non-responsive disease despite biologic therapies. Different drugs from the same class (for example anti-TNF-alpha blockers) may provide further treatment options. If a patient develops an $\mathrm{AE}$ from one 
TNF-alpha blocker, they can be switched to a different TNF alpha blocker or to another class of drugs (for example, B-cell modulators). Furthermore, if there was an initial efficacy response that ceased over time, a switch to a different biologic class may achieve a favorable result. With the various available biologic therapies, the therapy can be tailored to the individual patient. For example, IV therapy may be suitable for patients who need medical supervision, whereas SC therapy may be suitable for patients who feel confident injecting the drug in the privacy of their own home. In addition, the choice of biologic may be customized to include considerations of co-morbidities or the need for concomitant drug treatment. There is a focus on early treatment, yet none of the biologic therapies is yet available as first-line medication for autoimmune diseases, probably due to economic concerns. Because the complexity of preparing biologic drugs has diminished over the years, costs may be driven down, allowing biologic therapies to be used at an early stage of disease and hence enable prevention of irreversible damage.

\section{Conclusions}

The arsenal of biologic therapies available to treat autoimmune diseases is quickly expanding as a result of better understanding of molecular mechanisms together with improved production capacity. They include (by class): novel anti-TNF alpha blockers (fully humanized or pegylated), anti-IL agents (to IL-1, IL-6), B-cell-directed therapies (to CD20, CD22), co-activation signaling (CTLA4-Ig), and IVIG. Although most of the FDA-approved biologic therapies are for RA, Belimumab is the first FDA-approved targeted therapy for SLE. In addition, the efficacy and safety for biologics in off-label indications are encouraging for patients with resistant autoimmune conditions.

\footnotetext{
Abbreviations

ACR: American College of Rheumatology; Anti-TNF: Tumor necrosis factor antagonist; AS: Ankylosing spondylitis; ASAS: Assessment in Ankylosing Spondylitis; BLySS: B lymphocyte stimulator; BILAG: British Isles Lupus Assessment Group; CRP: C-reactive protein; DAS28: 28-item Disease Activity Score; DMARD: Disease-modifying anti-rheumatic drug; EC50: Half-maximal effective concentration; Gl: Gastrointestinal; HAQ: Health Assessment Questionnaire; IFN: Interferon; ITP: Immune thrombocytopenic purpura; IVIG: IV immunoglobulin; JIA: Juvenile idiopathic arthritis; MTX: Methotrexate; MPA: Microscopic polyangiitis; RA: Rheumatoid arthritis; RCT: Randomized controlled trial; SAA: Sserum amyloid A; SELENA-SLEDAI: Safety of Estrogens in Lupus Erythematosus National Assessment-Systemic Lupus Erythematosus Disease Activity Index; SJIA: Systemic juvenile idiopathic arthritis; TB: Tuberculosis; TCZ: Tocilizumab; TNF: Tumor necrosis factor.alpha; URT: Upper respiratory tract.
}

\section{Competing interests}

The authors do not have any competing interests.

\section{Authors' contributions}

RZ and ZGG contributed equally to the literature search, review of the pertinent articles, and writing of the article. SY contributed to the concept, editing, and critical appraisal of the article. All authors read and approved the manuscript for publication.

\section{Author details}

'Department of Medicine C, Wolfson Medical Center, 61 Halochamim Street, POB 63, Holon, 58100 Israel. 'Zabludowicz Center for Autoimmune Diseases, Sheba Medical Center, Sheba 2, Ramat-Gan, Israel. ${ }^{3}$ Sackler Faculty of Medicine, Tel-Aviv University, Tel-Aviv, Israel.

Received: 14 June 2012 Accepted: 11 January 2013

Published: 4 April 2013

\section{References}

1. Burmester GR, Feist E, Kellner H, Braun J, Iking KC, Roth AR: Effectiveness and safety of the interleukin 6-receptor antagonist tocilizumab after 4 and 24 weeks in patients with active rheumatoid arthritis: the first phase Illb real-life study (TAMARA). Ann Rheum Dis 2011, 70:755-759.

2. Hashizume M, Mihara M: The roles of interleukin- 6 in the pathogenesis of rheumatoid arthritis. Arthritis 2011, 2011:765624. doi:10.1155/2011/765624.

3. Nisar MK, Östör JKA: The role of tocilizumab monotherapy in the management of rheumatoid arthritis: a review. Int I Clin Rheumatol 2012, 7:9-19.

4. Uchiyama Y, Yorozu K, Hashizume M, Moriya Y, Mihara M: Tocilizumab, a humanized anti-interleukin-receptor antibody, ameliorates joint swelling in established monkey collagen-induced arthritis. Biol Pharm Bull 2008, 31:1159-1163

5. Levi M, Grange S, Frey N: Exposure-response relationship of tocilizumab, an anti-IL-6 receptor monoclonal antibody, in a large population of patients with rheumatoid arthritis. J Clin Pharmacol 2012. Feb 14. [Epub ahead of print].

6. Ogata A, Tanaka T: Tocilizumab for the treatment of rheumatoid arthritis and other systemic autoimmune diseases: current perspectives and future directions. Int J Rheumatol. 2012, 2012:946048.

7. Nishimoto N, Miyasaka N, Yamamoto K, Kawai S, Takeuchi T, Azuma J: Longterm safety and efficacy of tocilizumab, an anti-IL-6 receptor monoclonal antibody, in monotherapy, in patients with rheumatoid arthritis (the STREAM study): evidence of safety and efficacy in a 5-year extension study. Ann Rheum Dis 2009, 68:1580-1584

8. Bergman GJD, Hochberg MC, Boers M, Wintfeld N, Kielhorn A, Jansen JP: Indirect comparison of tocilizumab and other biologic agents in patients with rheumatoid arthritis and inadequate response to disease-modifying antirheumatic drugs. Semin Arthritis Rheum 2010, 39:425-441.

9. Tak PP, Kalden JR: Advances in rheumatology: new targeted therapeutics. Arthritis Res Ther 2011, 13(Suppl 1):S5.

10. Schiff MH, Kremer JM, Jahreis A, Vernon E, Isaacs JD, Van Vollenhoven RF: Integrated safety in tocilizumab clinical trials. Arthritis Res Ther 2011, 13:R141

11. Singh JA, Wells GA, Christensen R, Tanjong Ghogomu E, Maxwell L, Macdonald JK, Filippini G, Skoetz N, Francis D, Lopes LC, Guyatt GH, Schmitt J, La Mantia L, Weberschock T, Roos JF, Siebert H, Hershan S, Lunn MP, Tugwell P, Buchbinder R: Adverse effects of biologics: a network metaanalysis and Cochrane overview. Cochrane Database Syst Rev 2011, 16:CD008794.

12. Verweij $\mathrm{CL}$, Vosslamber $\mathrm{S}$ : New insight in the mechanism of action of rituximab: the interferon signature towards personalized medicine. Discov Med 2011, 12:229-236.

13. Mease PJ, Cohen S, Gaylis NB, Chubick A, Kaell AT, Greenwald M, Agarwal S, Yin $M$, Kelman A: Efficacy and safety of retreatment in patients with rheumatoid arthritis with previous inadequate response to tumor necrosis factor inhibitors: results from the SUNRISE Trial. J Rheumatol 2010, 37:917-927.

14. Stone JH, Merkel PA, Spiera R, Seo P, Langford CA, Hoffman GS, Kallenberg CG, St Clair EW, Turkiewicz A, Tchao NK, Webber L, Ding L, Sejismundo LP, Mieras K, Weitzenkamp D, Ikle D, Seyfert MV, Mueller M, Brunetta P, Allen NB, Fervenza FC, Geetha D, Keogh KA, Kissin EY, Monach PA, Peikert T, Stegeman C, Ytterberg SR, Specks U, RAVE-ITN Research Group: Rituximab versus Cyclophosphamide for ANCA-associated vasculitis. N Engl J Med 2010, 363:221-232.

15. Palau J, Jarque I, Sanz MA: Long-term management of chronic immune thrombocytopenic purpura in adults. Int J Gen Med 2010, 3:305-311.

16. Cianchini G, Lupi F, Masini C, Corona R, Puddu P, De Pità O: Therapy with rituximab for autoimmune pemphigus: results from a single-center observational study on 42 cases with long-term follow-up. J Am Acad Dermatol 2012, 67:617-622. 
17. Daoussis D, Liossis SN, Yiannopoulos G, Andonopoulos AP: B-cell depletion therapy in systemic sclerosis: experimental rationale and update on clinical evidence. Int J Rheumatol 2011, 2011:214013.

18. Merrill JT, Neuwelt CM, Wallace DJ, Shanahan JC, Latinis KM, Oates JC, Utset TO, Gordon C, Isenberg DA, Hsieh HJ, Zhang D, Brunetta PG: Efficacy and safety of rituximab in moderately-to-severely active systemic lupus erythematosus: the randomized, double-blind, phase II/III systemic lupus erythematosus evaluation of rituximab trial. Arthritis Rheum 2010, 62:222-233.

19. Tew GW, Rabbee N, Wolslegel K, Hsieh HJ, Monroe JG, Behrens TW, Brunetta $P G$, Keir ME: Baseline autoantibody profiles predict normalization of complement and anti-dsDNA autoantibody levels following rituximab treatment in systemic lupus erythematosus. Lupus 2010, 19:146-157.

20. Wallace DJ: Advances in drug therapy for systemic lupus erythematosus. BMC Med 2010, 8:77.

21. Van Vollenhoven RF, Emery P, Bingham CO 3rd, Keystone EC, Fleischmann R, Furst DE, Macey K, Sweetser M, Kelman A, Rao R: Long term safety of patients receiving rituximab in rheumatoid arthritis clinical trials. J Rheumatol 2010, 37:558-567.

22. Fonseca JE, Bernardes $M$, Canhão $H$, Santos MJ, Quintal A, Malcata A, Neto A, Cordeiro A, Rodrigues A, Mourão AF, Ribeiro AS, Cravo AR, Barcelos A, Cardoso A, Vilar A, Braña A, Faustino A, Silva C, Duarte C, Araújo D, Nour D, Sousa E, Simões E, Godinho F, Brandão F, Ventura F, Sequeira G, Fiqueiredo G, Cunha I, Matos JA, et al: Portuguese guidelines for the use of biological agents in rheumatoid arthritis - October 2011 update. Acta Reumatol Port 2011, 36:385-388.

23. Isvy A, Meunier M, Gobeaux-Chenevier C, Maury E, Wipff J, Job-Deslandre C, Kahan A, Allanore Y: Safety of rituximab in rheumatoid arthritis: a longterm prospective single-center study of gammaglobulin concentrations and infections. Joint Bone Spine 2012, 79:365-369.

24. Ostergaard M, Baslund B, Rigby W, Rojkovich B, Jorgensen C, Dawes PT, Wiell C, Wallace DJ, Tamer SC, Kastberg H, Petersen J, Sierakowski S: Ofatumumab, a human anti-CD20 monoclonal antibody, for treatment of rheumatoid arthritis with an inadequate response to one or more disease-modifying antirheumatic drugs: results of a randomized, doubleblind, placebo-controlled, phase I/II study. Arthritis Rheum 2010, 62:2227-2238

25. Taylor PC, Quattrocchi E, Mallett S, Kurrasch R, Petersen J, Chang DJ: Ofatumumab, a fully human anti-CD20 monoclonal antibody, in biological-naive, rheumatoid arthritis patients with an inadequate response to methotrexate: a randomised, double-blind, placebocontrolled clinical trial. Ann Rheum Dis 2011, 70:2119-2125.

26. Wallace DJ, Stohl W, Furie RA, Lisse JR, McKay JD, Merrill JT, Petri MA, Ginzler EM, Chatham WW, McCune WJ, Fernandez V, Chevrier MR, Zhong ZJ Freimuth WW: A phase II, randomized, double-blind, placebo-controlled, dose-ranging study of belimumab in patients with active systemic lupus erythematosus. Arthritis Rheum 2009, 61:1168-1178.

27. Navarra SV, Guzmán RM, Gallacher AE, Hall S, Levy RA, Jimenez RE, Li EK, Thomas M, Kim HY, León MG, Tanasescu C, Nasonov E, Lan JL, Pineda L, Zhong ZJ, Freimuth W, Petri MA, BLISS-52 Study Group: Efficacy and safety of belimumab in patients with active systemic lupus erythematosus: a randomised, placebo-controlled, phase 3 trial. Lancet 2011, 377:721-731.

28. Traczewski $P$, Rudnicka L: Treatment of systemic lupus erythematosus with epratuzumab. Br J Clin Pharmacol 2011, 71:175-182

29. Dörner T, Goldenberg DM: Targeting CD22 as a strategy for treating systemic autoimmune diseases. Ther Clin Risk Manag 2007, 3:953-959.

30. Wallace DJ, Kalunian KC, Petri MA, Strand V, Kilgallen B, Barry A, Gordon C: Epratuzumab demonstrates clinically meaningful improvements in patients with moderate to severe systemic lupus erythematosus (SLE): results from $\mathrm{Emblem}^{\mathrm{TM}}$, a phase Ilb study. [abstract]. 9th International Congress on Systemic Lupus Erythematosus. June 24-27, 2010, Vancouver, Canada

31. Kremer JM, Dougados M, Emery P, Durez P, Sibilia J, Shergy W, Steinfeld S, Tindall E, Becker JC, Li T, Nuamah IF, Aranda R, Moreland LW: Treatment of rheumatoid arthritis with the selective costimulation modulator abatacept: twelve-month results of a phase $\mathrm{Ilb}$, double-blind randomized, placebo-controlled trial. Arthritis Rheum 2005, 52:2263-2271.

32. Merrill JT, Burgos-Vargas R, Westhovens R, Chalmers A, D'Cruz D, Wallace DJ, Bae SC, Sigal L, Becker JC, Kelly S, Raghupathi K, Li T, Peng Y, Kinaszczuk M, Nash P: The efficacy and safety of abatacept in patients with non-life -threatening manifestations of systemic lupus erythematosus: results of a twelve-month, multicenter, exploratory, phase $\mathrm{llb}$, randomized, double-blind, placebo-controlled trial. Arthritis Rheum 2010, 62:3077-3087.

33. Nogid A, Pham DQ: Role of abatacept in the management of rheumatoid arthritis. Clin Ther 2006, 28:1764-1778.

34. Genovese MC, Becker JC, Schiff M, Luggen M, Sherrer Y, Kremer J, Birbara C, Box J, Natarajan K, Nuamah I, Li T, Aranda R, Hagerty DT, Dougados M: Abatacept for rheumatoid arthritis refractory to tumor necrosis factor alpha inhibition. N Engl J Med 2005, 353:1114-1123.

35. Kremer JM, Russell AS, Emery P, Abud-Mendoza C, Szechinski J, Westhovens R, Li T, Zhou X, Becker JC, Aranda R, Peterfy C, Genant HK: Long-term safety, efficacy and inhibition of radiographic progression with abatacept treatment in patients with rheumatoid arthritis and an inadequate response to methotrexate: 3-year results from the AIM trial. Ann Rheum Dis 2011, 70:1826-1830.

36. Inman RD, Davis JC Jr, van der Heijde D, Diekman L, Sieper J, Kim SI, Mack M, Han J, Visvanathan S, Xu Z, Hsu B, Beutler A, Braun J: Efficacy and safety of golimumab in patients with ankylosing spondylitis, results of a randomized, double-blind, placebo-controlled, phase III trial. Arthritis Rheum 2008, 58:3402-3412.

37. Kavanaugh A, Mcinnes I, Mease P, Krueger GG, Gladman D, Gomez-Reino J, Papp K, Zrubek J, Mudivarthy S, Mack M, Visvanathan S, Beutler A: Golimumab, a new human tumor necrosis factor a antibody, administered every four weeks as a subcutaneous injection in psoriatic arthritis, twenty-four-week efficacy and safety results of a randomized, placebo-controlled study. Arthritis Rheum 2009, 60:976-986.

38. Keystone EC, Genovese MC, Klareskog L, Hsia EC, Hall ST, Miranda PC, Pazdur J, Bae SC, Palmer W, Zrubek J, Wiekowski M, Visvanathan S, Wu Z, Rahman MU: Golimumab, a human antibody to TNF- a given by monthly subcutaneous injections, in active rheumatoid arthritis despite methotrexate: the GO-FORWARD Study. Ann Rheum Dis 2009, 68:789-796.

39. Emery P, Fleischmann RM, Moreland LW, Hsia EC, Strusberg I, Durez P, Nash P, Amante EJ, Churchill M, Park W, Pons-Estel BA, Doyle MK, Visvanathan S, Xu W, Rahman MU: Golilumab, a human anti-tumor necrosis factor a monoclonal antibody, injected subcutaneously every four weeks in methotrexate naïve patients with rheumatoid arthritis. Arthritis Rheum 2009, 60:2272-2283.

40. Ash Z, Emery P: Golilumab- a new tool in the armoury against inflammatory arthritis. Ann Med 2011, 43:133-141.

41. Smolen J, Landewé RB, Mease P: Efficacy and safety of certolizumab pegol plus methotrexate in active rheumatoid arthritis: the RAPID 2 study. A randomised controlled trial. Ann Rheum Dis 2009, 68:797-804.

42. Fleischmann R, Vencovsky J, van Vollenhoven RF, Borenstein D, Box J, Coteur G, Goel N, Brezinschek HP, Innes A, Strand V: Efficacy and safety of certolizumab pegol monotherapy every 4 weeks in patients with rheumatoid arthritis failing previous disease-modifying antirheumatic therapy: the FAST4WARD study. Ann Rheum Dis 2009, 68:805-811.

43. Yao Y, Richman L, Higgs BW, Morehouse CA, De Los Reyes M, Brohawn P, Zhang J, White B, Coyle AJ, Kiener PA, Jallal B: Neutralization of interferonalpha/beta-inducible genes and downstream effect in a phase I trial of an anti-interferon-alpha monoclonal antibody in systemic lupus erythematosus. Arthritis Rheum 2009, 60:1785-1796.

44. Merrill JT, Wallace DJ, Petri M, Kirou KA, Yao Y, White WI, Robbie G, Levin R, Berney SM, Chindalore V, Olsen N, Richman L, Le C, Jallal B, White B, Lupus Interferon Skin Activity (LISA) Study Investigators: Safety profile and clinical activity of sifalimumab, a fully human anti-interferon a monoclonal antibody, in systemic lupus erythematosus: a phase I, multicentre, double-blind randomised study. Ann Rheum Dis 2011, 70:1905-1913.

45. Kuemmerle-Deschner JB, Hachulla E, Cartwright R, Hawkins PN, Tran TA, Bader-meunier B, Hoyer J, Gattorno M, Gul A, Smith J, Leslie KS, Jimenez S, Morell-Dubois S, Davis N, Patel N, Widmer A, Preiss R, Lachmann HJ: Twoyear results from an open-label, multicentre, phase III study evaluating the safety and efficacy of canakinumab in patients with cryopyrinassociated periodic syndrome across different severity phenotypes. Ann Rheum Dis 2011, 70:2095-2102.

46. Hoffman HM, Throne ML, Amar NJ, Cartwright RC, Kivitz AJ, Soo Y, Weinstein SP: Long-term efficacy and safety profile of rilonacept in the treatment of cryopyrin-associated periodic syndromes: results of a 72 week open-label extension study. Clin Ther 2012, 34:2091-2103.

47. So A, De Meulemeester M, Pikhlak A, Yücel AE, Richard D, Murphy V: Canakinumab for the treatment of acute flares in difficult-to-treat gouty arthritis: results of a multicenter, phase II, dose-ranging study. Arthritis Rheum 2010, 62:3064-3076. 
48. Kivity S, Katz U, Daniel N, Nussinovitch U, Papageorgiou N, Shoenfeld Y: Evidence for the use of intravenous immunoglobulins-a review of the literature. Clin Rev Allergy Immunol 2010, 38:201-269.

49. Katz $U$, Zandman-Goddard G: Update on intravenous immunoglobulins (IVlg) mechanisms of action and off-label use in autoimmune diseases. Curr Pharm Des 2011, 17:3166-3175.

50. Zandman-Goddard G, Krauthammer A, Levy Y, Langevitz P, Shoenfeld Y: Long-term therapy with intravenous immunoglobulin is beneficial in patients with autoimmune diseases. Clin Rev Allergy Immunol 2012, 42:247-255.

51. Rosman Z, Zandman-Goddard G: Intravenous immunoglobulin therapy for SLE. Future Medicine 2012. doi:10.2217/ebo.11.328.

52. Sherer Y, Kuechler S, Jose Scali J, Rovensky J, Levy Y, Zandman-Goddard G, Shoenfeld $Y$ : Low dose intravenous immunoglobulin in systemic lupus erythematosus: analysis of 62 cases. Isr Med Assoc J 2008, 10:55-57.

53. Levy $Y$, Sherer $Y$, Ahmed A, Langevitz P, George J, Fabbrizzi F, Terryberry J, Meissner M, Lorber M, Peter JB, Shoenfeld Y: A study of 20 SLE patients with intravenous immunoglobulin-clinical and serologic response. Lupus 1999, 8:705-712.

54. Zandman-Goddard G, Levy Y, Shoenfeld Y: Intravenous immunoglobulin therapy and systemic lupus erythematosus. Clin Rev Allergy Immunol 2005, 29:219-228.

55. Orbach $H$, Tishler $M$, Shoenfeld $Y$ : Intravenous immunoglobulin and the kidney-a two-edged sword. Semin Arthritis Rheum 2004, 34:593-601.

56. Zandman-Goddard G, Krauthammer A, Shoenfeld Y: The steroid-sparing effect of intravenous immunoglobulin in patients with autoimmune diseases. Expert Rev Clin Immunol 2007, 3:773-780.

57. Levy $Y$, Uziel $Y$, Zandman-Goddard G, Rotman $P$, Amital $H$, Sherer $Y$, Langevitz P, Goldman B, Shoenfeld Y: Response of vasculitic peripheral neuropathy to intravenous immunoglobulin. Ann N Y Acad Sci 2005, 1051:779-786.

58. Katz U, Achiron A, Sherer $Y$, Shoenfeld $Y$ : Safety of intravenous immunoglobulin (IVIG) therapy. Autoimmun Rev 2007, 6:257-259.

59. Katz U, Zandman-Goddard G: Drug-induced lupus: an update. Autoimmun Rev 2010, 10:46-50.

doi: 10.1186/1741-7015-11-88

Cite this article as: Rosman et al:: Biologic therapy for autoimmune diseases: an update. BMC Medicine 2013 11:88.

\section{Submit your next manuscript to BioMed Central and take full advantage of:}

- Convenient online submission

- Thorough peer review

- No space constraints or color figure charges

- Immediate publication on acceptance

- Inclusion in PubMed, CAS, Scopus and Google Scholar

- Research which is freely available for redistribution 